ARTICLE

Received 13 Jan 2015 | Accepted 12 Sep 2015 | Published 21 Oct 2015

DOI: $10.1038 /$ ncomms 9618

\title{
Quantifying the density and utilization of active sites in non-precious metal oxygen electroreduction catalysts
}

Nastaran Ranjbar Sahraie ${ }^{1, \star}$, Ulrike I. Kramm ${ }^{2,3, \star}$, Julian Steinberg${ }^{1}$, Yuanjian Zhang ${ }^{4}$, Arne Thomas ${ }^{5}$, Tobias Reier ${ }^{1}$, Jens-Peter Paraknowitsch ${ }^{5} \&$ Peter Strasser $^{1}$

Carbon materials doped with transition metal and nitrogen are highly active, non-precious metal catalysts for the electrochemical conversion of molecular oxygen in fuel cells, metal air batteries, and electrolytic processes. However, accurate measurement of their intrinsic turn-over frequency and active-site density based on metal centres in bulk and surface has remained difficult to date, which has hampered a more rational catalyst design. Here we report a successful quantification of bulk and surface-based active-site density and associated turn-over frequency values of mono- and bimetallic $\mathrm{Fe} / \mathrm{N}$-doped carbons using a combination of chemisorption, desorption and ${ }^{57} \mathrm{Fe}$ Mössbauer spectroscopy techniques. Our general approach yields an experimental descriptor for the intrinsic activity and the active-site utilization, aiding in the catalyst development process and enabling a previously unachieved level of understanding of reactivity trends owing to a deconvolution of site density and intrinsic activity.

\footnotetext{
${ }^{1}$ Department of Chemistry, The Electrochemical Energy, Catalysis and Material Science Laboratory, Chemical Engineering Division, Technical University Berlin, Straße des 17. Juni 124, 10623 Berlin, Germany. ${ }^{2}$ Department of Chemistry, Technical University Darmstadt, Jovanka-Bontschits-Street 2, 64287 Darmstadt, Germany. ${ }^{3}$ Department of Materials and Earth Science, Technical University Darmstadt, Jovanka-Bontschits-Street 2, 64287 Darmstadt, Germany. ${ }^{4}$ School of Chemistry and Chemical Engineering, Southeast University, Nanjing 211189, China. ${ }^{5}$ Department of Chemistry, Division of Functional Materials, Technical University Berlin, Hardenbergstr. 40, 10623 Berlin, Germany. * These authors contributed equally to this work. Correspondence and requests for materials should be addressed to U.I.K. (email: kramm@ese.tu-darmstadt.de) or to P.S. (email: pstrasser@tu-berlin.de).
} 
T he electrochemical reduction of oxygen ('oxygen reduction reaction', ORR) in acid and alkaline environments is a tremendously important reaction for a variety of emerging electrochemical energy technologies and device components such as cathodes of metal air batteries ${ }^{1}$ and fuel cells $^{2-5}$, or oxygen depolarization cathodes in brine and hydrochloric acid electrolysers ${ }^{6}$. However, sluggish ORR kinetics causes prohibitively high-energy efficiency losses. Presently, platinum and its alloys are widely used in fuel cells; however, the scarcity of Pt calls for a replacement of this costly noble metal with less expensive metals (Me) such as iron, cobalt and manganese in the form of Me-N-C catalysts ${ }^{7-9}$. To achieve this goal, a rational design of non-precious metal catalysts (NPMC) with superior activity over $\mathrm{Pt}$ materials and stability has attracted much attention $^{2,5,10-12}$. Recently, significant advances have been made in improving the activity of NPMCs to the levels comparable to Pt-based materials ${ }^{2,13}$. Evidence is mounting that the key structural motif of these catalysts are nitrogen-coordinated transition metal ions of $\mathrm{MeN}_{x}(x=2 \ldots 4)$ embedded in basal planes of carbon or bridging two graphene planes at their edges $8,14-20$. NPMCs still suffer from poor durability ${ }^{2,4,11,21,22}$, which is in part attributed to corrosion of the carbon support and the active sites by by-products such as $\mathrm{H}_{2} \mathrm{O}_{2}$. Accordingly, current key goals in non-precious metal ORR catalysis comprise molecular insight in the catalytically active site ${ }^{15,23}$, optimized synthesis and interrogation tools for the active-site density, as well as strategies to stabilize the active catalytic sites during oxygen reduction $5,9,24,25$. In this respect, particular attention was placed on a specific family of Me-N-C catalysts derived from high-nitrogen content molecules, such as cyanamide and from heterocyclic polymers such as polyaniline (PANI), or combinations thereof $5,9,25$.

A recent report by Zelenay and co-workers ${ }^{5}$ addressed possible benefits of a bimetallic active site to improve the final stability of the catalysts. They showed that simultaneous utilization of Co and Fe precursors can increase the stability of the catalyst in acid electrolyte.

Our incomplete understanding of the role of the metal ion in the active-site structure originates in large parts from the lack of a suitable technique to probe the chemical composition, density and reactivity of the active sites in these types of catalysts. Molecular probes, such as cyanide and carbon monoxide, have been used in a number of unsuccessful efforts to poison active catalytic sites in rotating disk electrode (RDE) measurements ${ }^{26-28}$. At room temperature results showed no measurable deactivation effect on catalyst performance in the presence of $\mathrm{CO}$ as typically seen for Pt-containing catalysts. Hence, probing active sites under RDE condition using $\mathrm{CO}$ has not been a viable strategy to probe this type of NPMCs.

In the present work, we use PANI-derived $\mathrm{Me}-\mathrm{N}-\mathrm{C}$ catalyst materials as model systems to demonstrate the benefit of a combined active-site analysis by Mössbauer spectroscopy and $\mathrm{CO}$ pulse chemisorption/desorption. Unlike earlier studies, lowtemperature $\mathrm{CO}$ pulse chemisorption and temperatureprogrammed desorption (TPD) are successfully applied as chemical interrogation tools to obtain quantitative insights into the density of active adsorption sites of the catalysts. To the best of our knowledge, this is the first time that pulse chemisorption and TPD are successfully applied to quantify surface adsorption sites of Me-N-C materials. Our analysis correlates the active-site density with the apparent catalytic reactivity in acid and alkaline media, yielding surface site-based metal-specific catalytic turnover frequencies (TOFs). In combination with ${ }^{57} \mathrm{Fe}$ Mössbauer spectroscopy, we derive a measure for the active-site utilization of the (Fe-based) NPMCs, quantifying the limits of further activity enhancement. Moreover, the direct comparison of TOFs of mono- and bimetallic catalysts uncovers previously unexplored synergistic effects between two dissimilar metal ions in the enhancement of the ORR activity in alkaline.

\section{Results}

Catalytic oxygen reduction activity and stability. Figure 1 displays the catalytic ORR performances of the $\mathrm{Fe}-\mathrm{N}-\mathrm{C}$, the $\mathrm{Mn}-\mathrm{N}-\mathrm{C}$ and the bimetallic (Fe,Mn)-N-C catalysts (each after 3 heat treatment (HT) and 2 acid leaching (AL) steps, following our notation) in acid and alkaline electrolytes. The preparation of the catalysts, partially encoded in their notation, is illustrated in Supplementary Fig. 1. The shape and diffusion-limiting currents of the voltammetric sweeps (Fig. 1a,c) are consistent with a four-electron reduction of $\mathrm{O}_{2}$ to $\mathrm{H}_{2} \mathrm{O}$, while their Tafel Plots (Fig. 1b,d) evidence some of the highest catalytic activities ever recorded at low and high $\mathrm{pH}^{5,9,25}$.

The mass activity, onset-potential and half-wave potential of these three catalysts, Me-N-C-3HT-2AL, are listed in Supplementary Tables 1 and 2 together with their mother samples, that is, $2 \mathrm{HT}-1 \mathrm{AL}$. The ORR activity increased or remained constant with these final AL and HT steps, even though the overall metal content decreased by about $50 \%$ for all three catalysts during this treatment (Supplementary Table 3). On a first view, this is consistent with the notion that ORR inactive species are gradually removed by iterative HT-AL cycles. It is further supported by X-ray powder diffraction data in Supplementary Fig. 2: while crystalline sulphides dominate the X-ray pattern after the first $\mathrm{HT}$, all sulphide-related diffraction fingerprints vanished after the final third HT. In the diffractograms, only broad reflexes assigned to a micrographitization of the final catalysts remained visible (Supplementary Fig. 2). In line with this observation, we note that non-precious ORR catalysts reported earlier, derived from singly-leached PANI-Fe-C composites (prepared by a $2 \mathrm{HT}-1 \mathrm{AL}$ cycle), still did contain substantial amounts of residual ORR catalytically inactive crystalline sulphides and thus performed inferior to the present materials ${ }^{5,14}$.

To assess the stability of the catalysts, we performed a severe accelerated stress test (AST) by cycling the potential between $0.5 \mathrm{~V}_{\mathrm{RHE}}$ and $1.3 \mathrm{~V}_{\mathrm{RHE}}$ (see Methods section for further details). The results are summarized in Fig. 2a,b. In acid environment, as expected due to the oxidizing potential of $1.3 \mathrm{~V}$, a substantial decrease in catalytic ORR activity occurred for both monometallic catalysts ( $-19 \%$ for $\mathrm{Fe}-\mathrm{N}-\mathrm{C}-3 \mathrm{HT}-2 \mathrm{AL}$ and $-67 \%$ for $\mathrm{Mn}-\mathrm{N}-$ C-3HT-2AL). In alkaline environment, both monometallic catalysts performed more stable as in acid environment, with a drop of $-2 \%$ for Fe-N-C-3HT-2AL and $-14 \%$ for $\mathrm{Mn}-\mathrm{N}-\mathrm{C}-$ 3HT-2AL. In contrast, the bimetallic $(\mathrm{Fe}, \mathrm{Mn})-\mathrm{N}-\mathrm{C}-3 \mathrm{HT}-2 \mathrm{AL}$ catalyst exhibited favourable performance stability in both acid $(-4 \%)$ and alkaline $(-1 \%)$ environments. We attribute this exceptional stability to a possible synergistic effect brought about by co-doping with two dissimilar transition metals. The electrochemical data in Figs 1 and 2 bear testimony to the promising ORR catalytic performance characteristic of the novel family of bimetallic ( $\mathrm{Fe}, \mathrm{Mn})-\mathrm{N}-\mathrm{C}$ materials.

The fuel cell polarization curves, cycling stability plots $\left(\mathrm{O}_{2}-\mathrm{H}_{2}\right)$ and the relative change in activity in dependence on the cycle number are shown in Supplementary Fig. 3 for our Fe- and $(\mathrm{Fe}, \mathrm{Mn})-\mathrm{N}-\mathrm{C}-3 \mathrm{HT}-2 \mathrm{AL}$ catalysts. The trends in activity are in good agreement with RDE measurements (Fig. 1). Comparing our catalyst with today's most active $\mathrm{Fe}-\mathrm{N}-\mathrm{C}$ catalyst published by Jean-Pol Dodelet's group, we have to make the following conclusions: while reaching even higher geometric current densities in $\mathrm{RDE}$ conditions $^{29}$, the surface-specific current densities of our catalysts are far of that catalyst in Proton 
Exchange Membrane Fuel Cell (PEM FC) ${ }^{2}$. This most active Fe$\mathrm{N}-\mathrm{C}$ is still not reaching the performance of $\mathrm{Pt} / \mathrm{C}^{2}$. With having these outstanding performance in $\mathrm{RDE}$, we assume that an optimization of the ink receipt (specifically the Nafion to Catalyst ratio) might enable even more favourable ORR activities in FC too $^{29}$. The change of current as a function of cycle numbers is provided in Supplementary Fig. 3b,c and compared with data taken from Gang Wu et al. ${ }^{5}$, for a PANI-Fe-C catalyst degraded with an AST protocol close to ours. As compared with RDE the bimetallic catalyst $(\mathrm{Fe}, \mathrm{Mn})-\mathrm{N}-\mathrm{C}-3 \mathrm{HT}-2 \mathrm{AL}$ performs as stable or even more stable compared with $\mathrm{Fe}-\mathrm{N}-\mathrm{C}-3 \mathrm{HT}-2 \mathrm{AL}$ (at $\mathrm{U}>0.8 \mathrm{~V}$ ). It can be seen that both of our catalysts reveal under cycling conditions a similar stability compared with $\mathrm{Wu}$ et al. up to 10,000 cycles $^{5}$, while the absolute current density values are smaller.

Probing catalytically active sites in bulk and surface. To obtain atomic-scale insight into catalytically active Fe centres, the two Fe-containing catalysts were investigated using ${ }^{57} \mathrm{Fe}$ Mössbauer spectroscopy ${ }^{7,21,22}$. Figure 3 shows the Mössbauer spectra of the Fe and bimetallic Fe-Mn catalysts after 3HT-2AL, with Supplementary Table 4 summarizing the experimental Mössbauer parameters with detailed assignments of iron species. For reasons of comparison, their mother samples (2HT-1AL) are given in Supplementary Fig. 5.

The first two doublets are typical for $\mathrm{Fe}-\mathrm{N}-\mathrm{C}$ catalysts ${ }^{16,17,20,21,30}$. Their Mössbauer parameters are assigned to a ferrous low-spin $\mathrm{FeN}_{4}$ site (D1) and a ferrous intermediatespin $\mathrm{FeN}_{4}$ site (D2). In previous reports, the D1-related site was identified as ORR active site in $\mathrm{Fe}-\mathrm{N}-\mathrm{C}$ catalysts ${ }^{11,16,17,20,21,30}$.
Besides these two doublets, we found two additional doublets and a sextet. These were assigned to a $\left(\mathrm{NFe}^{\mathrm{III}} \mathrm{N}_{4}\right)-\mathrm{O}_{2}$ site $(\mathrm{D} 3)^{31}$, a ferrous high-spin $\mathrm{XY}-\mathrm{FeN}_{4}$ site (D4, X, Y represent two weak axial ligands as for example, oxygen or nitrogen $)^{20}$ and a small fraction of magnetic particles. The small magnetic field is an indication of reduced particle size $(<20 \mathrm{~nm})^{20,32}$, whereas its isomer shift indicates that the iron is in an oxidized state (most probable $\mathrm{Fe}^{3+}$ ). Induced by the reduced particle size, these particles appear X-ray amorphous. It should be noted that the Mössbauer parameters of our doublet D4 are close to values previously found for a $\mathrm{NFeN}_{2}+2 \ldots \mathrm{NH}^{+} / \mathrm{C}$ site $^{20,22}$. A comparison of the Mössbauer parameters is given in Supplementary Table 5, but illustrates that the isomer shift and quadrupole splitting of our D4 doublet are significantly higher (by $0.2 \mathrm{~mm} \mathrm{~s}^{-1}$ for $\delta_{\text {Iso }}$ and $0.4 \mathrm{~mm} \mathrm{~s}^{-1}$ for $\Delta \mathrm{E}_{\mathrm{Q}}$ ). In this case, the higher isomer shift is caused by the additional coordination of our $\mathrm{FeN}_{4}$ site by two weak ligands in comparison with the fivefoldcoordinated site $\mathrm{NFeN}_{2+2}$ in accordance with literature. Assuming that our D4 doublet should be assigned to that particular $\mathrm{FeN}_{2+2} \ldots \mathrm{NH}^{+} / \mathrm{C}$ site, a significantly larger mass-related activity for the $\mathrm{Fe}-\mathrm{N}-\mathrm{C}$ catalyst versus the bimetallic catalyst would be expected, as only the $\mathrm{Fe}-\mathrm{N}-\mathrm{C}$ catalyst contains this site that is reported as catalytically highly active one. In addition, this catalytic site is 'famous' for its fast deactivation, whereas all of our catalysts are rather stable in PEM-FC and RDE. Therefore, we assume that our $\mathrm{D} 4$ site is indeed different from that site.

With the isomer shifts, $\delta_{\text {iso, }}$ and the quadrupole splittings, $\Delta \mathrm{E}_{\mathrm{Q}}$, for the different iron sites being similar in all catalysts, we conclude that there is no evidence for an alloy-like electronic interaction between iron and manganese. On the other hand, the data evidenced that the two catalysts contained substantially
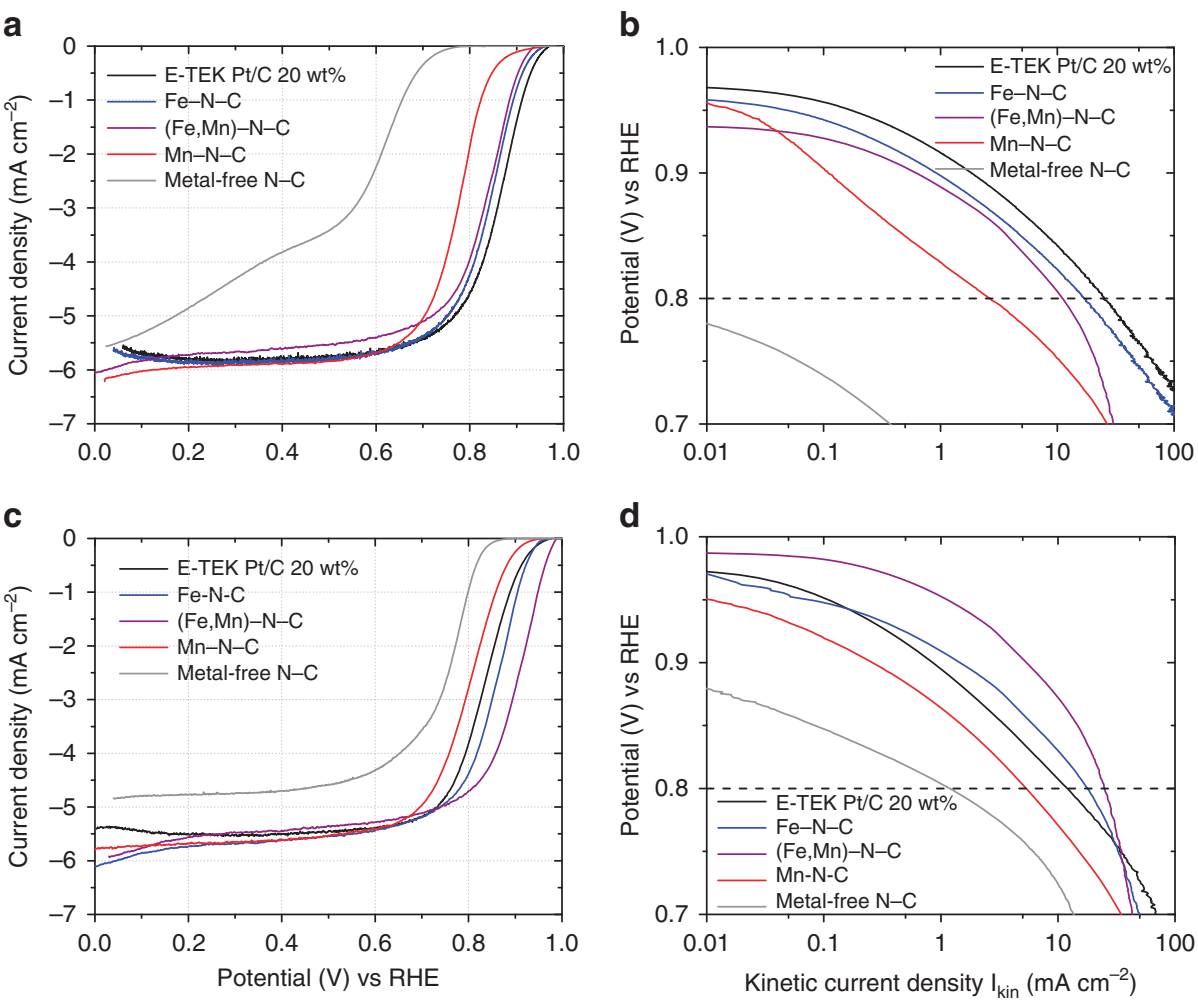

Figure 1 | Electrochemical activity evaluation. Linear Scan Voltammetry (LSV) of Me-N-C-3HT-2AL catalysts in oxygen-saturated acid (a) and alkaline (c) electrolytes. Electrochemical Tafel curves (applied $E$ versus $\log I_{k i n}$ ) derived from $\mathbf{a}$ and $\mathbf{c}$ in acid, $\mathbf{b}$ and $\mathbf{d}$ in alkaline are also given. For reasons of comparison the Me-N-C catalysts are compared with a commercial Pt/C catalyst and the metal-free N-C catalyst. Conditions: RDE experiment at 1,500 r.p.m., in $\mathrm{O}_{2}$-saturated $0.1 \mathrm{M} \mathrm{HClO}_{4}(\mathbf{a}, \mathbf{b})$ and $0.1 \mathrm{M} \mathrm{KOH}(\mathbf{c}, \mathbf{d}), 25^{\circ} \mathrm{C}$. Geometric catalyst loadings of NPMCs: $0.8 \mathrm{mg} \mathrm{cm}^{-2}$, and that of Pt/C: $50 \mu \mathrm{g} \mathrm{cm}^{-2}\left(10 \mu \mathrm{g}_{\mathrm{Pt}} \mathrm{cm}^{-2}\right)$. Measurements were repeated three times leading to the same results (Errors are given in Supplementary Tables 1 and 2). 

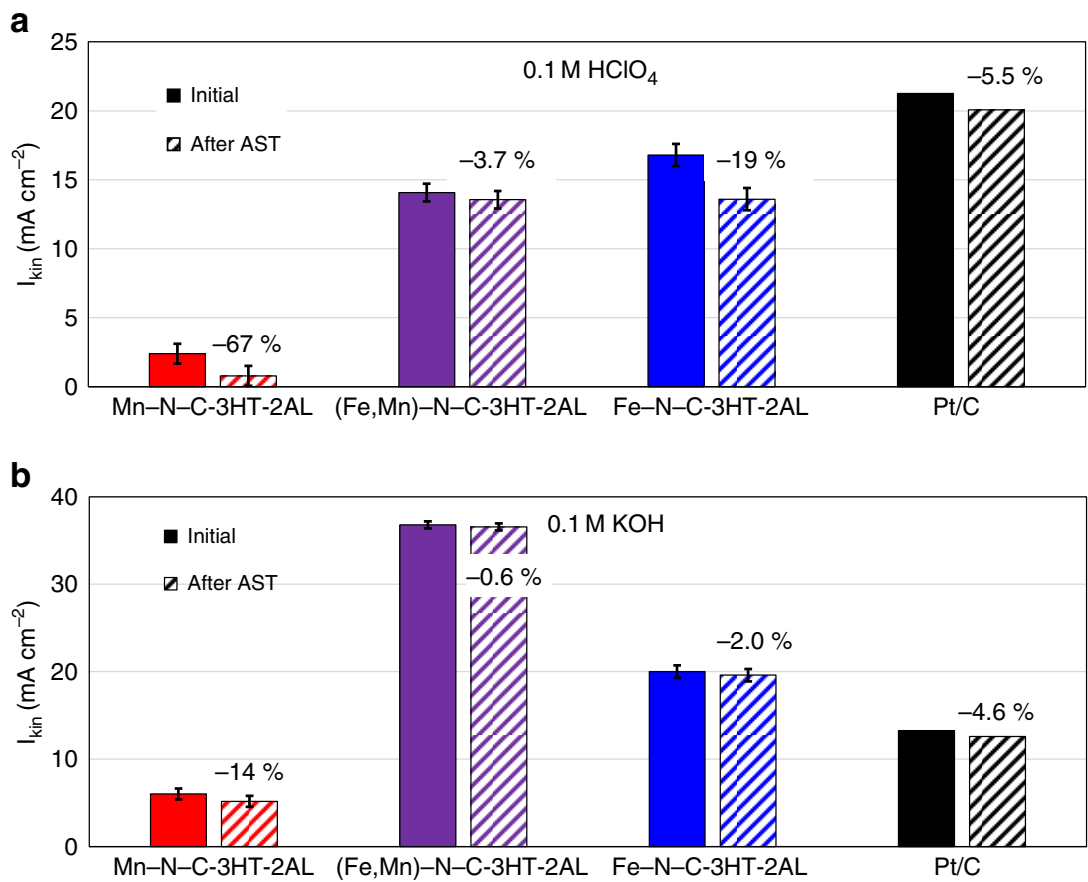

Figure 2 | Electrochemical stability evaluation. Kinetic current densities $I_{K i n}$ at $0.8 \mathrm{~V}\left(\mathrm{~mA} \mathrm{~cm}^{-2}\right)$ for the oxygen reduction reaction (ORR) of monoand bimetallic $\mathrm{Me}-\mathrm{N}-\mathrm{C}$ catalysts evaluated (a) in acid, $0.1 \mathrm{M} \mathrm{HClO}_{4}$ and (b) in alkaline, $0.1 \mathrm{M} \mathrm{KOH}$ before (solid) and after accelerated stress tests (AST; hatched); Accelerated stress tests involved 9,000 potential cycles between 0.5 and $1.3 \mathrm{~V}$ versus RHE with $50 \mathrm{mVs}^{-1}$ in $\mathrm{N}_{2}{ }^{-s a t u r a t e d}$ electrolyte. Error bars give the s.d. from the overall number of performed experiment.

a

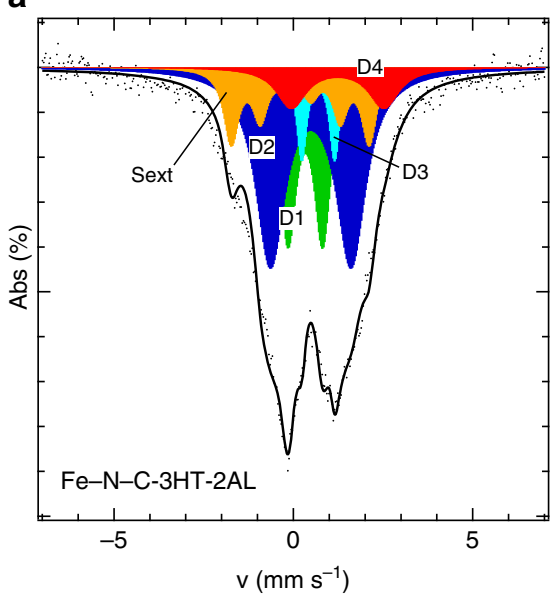

b

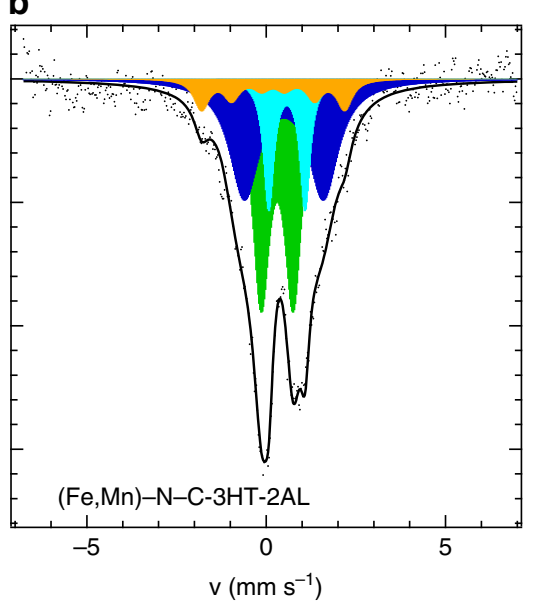

Figure 3 | Structural characterization of iron species. ${ }^{57} \mathrm{FeMössbauer}$ spectra of (a) Fe-N-C-3HT-2AL and (b) (Fe,Mn)-N-C-3HT-2AL.

The assignment to individual iron sites $D_{i}$ is indicated in $\mathbf{a}$. Detailed Mössbauer parameters and Fe concentration of each iron site are summarized in Supplementary Table 4.

smaller fractions of inorganic Fe species (here only oxidized iron particles) compared with PANI-based catalysts reported earlier ${ }^{5,14}$. Those catalysts contained significant fractions of $\mathrm{Fe}_{3} \mathrm{~S}_{4}$, iron nitride and iron carbide. We attribute the absence of these phases in our catalysts to the smaller amount of ammonium peroxidisulphate (APS) employed in the synthesis (ratio aniline:APS = 3:1 compared with 1:1 for the PANI-based catalysts of Zelenay's group). Consequently, other iron sulphide modifications were formed that were removed more effectively during AL. This effect was previously also found for other $\mathrm{Me}-\mathrm{N}-\mathrm{C}$ catalysts ${ }^{33,34}$. The Mössbauer spectra of the two Me-N-C-2HT-1AL catalysts in Supplementary Fig. 5 confirm this interpretation (note: for these two samples the preparation steps were similar to those performed by Zelenay's group).
From the relative absorption area of each iron site and the absolute iron content in the final catalyst, one can estimate the relative abundance of each type of iron site. These values are given in Supplementary Table 4, and will be used in the discussion part to derive a mass-based maximum site density $\left(\mathrm{MSD}_{\max }\right)$.

$\mathrm{X}$-ray photoelectron spectroscopy (XPS) was used to probe the near-surface nitrogen content of the $\mathrm{Me}-\mathrm{N}-\mathrm{C}$ catalysts. It confirmed the presence of a high fraction of nitrogen as required for the chemical coordination of the metal sites. Supplementary Figure 4 displays XPS survey spectra and N1s high resolution scans for all three catalysts. Supplementary Table 6 summarizes the related elemental composition. All three $\mathrm{Me}-\mathrm{N}-\mathrm{C}$ catalysts show distinct contributions of the $\mathrm{Me}-\mathrm{N}$ coordination in their 
N1s fine scans and varying contributions of pyridinic, pyrrolic, graphitic and oxidic nitrogen. For reasons of comparison, the metal-free $\mathrm{N}-\mathrm{C}$ catalyst was probed as well. Except for the metal species its elemental composition is similar to our Me-N-C catalysts. It should be noted that the contribution assigned as pyrrolic nitrogen is more pronounced in this catalyst, while the $\mathrm{Me}-\mathrm{N}_{x}$-peak is missing.

$\mathrm{X}$-ray absorption near edge spectroscopy (XANES) measurements were performed to characterize the Mn oxidation state in the two manganese-containing catalysts. In Supplementary Fig. 6, the XANES spectra of the $\mathrm{Mn} \mathrm{L}_{3,2}$ edge of both Mn-containing samples are compared. The catalysts reveal similar fine structures of two main contributions $\mathrm{A}_{1}, \mathrm{~A}_{2}$ that appear at $639 \mathrm{eV}, 640.5 \mathrm{eV}$ and $649 \mathrm{eV}, 651 \mathrm{eV}$, respectively, for the $\mathrm{L}_{3}$ and $\mathrm{L}_{2}$ edges. In addition, there are slight contributions $\mathrm{B}$ at $642.5 \mathrm{eV}$ for $\mathrm{L}_{3}$ (653 eV: $\mathrm{L}_{2}$-edge). The fine structure resembles that of $\mathrm{MnPc} / \mathrm{Au}$ measured under an incident beam angle of $30^{\circ}$, which is close to our experimental conditions. These energies describe the charge transfer from $\mathrm{Mn} 2 \mathrm{p}_{3 / 2}\left(\mathrm{~L}_{3}\right)$ and $2 \mathrm{p}_{1 / 2}\left(\mathrm{~L}_{2}\right)$ states into hybridized $\mathrm{Mnd}$-states ${ }^{35}$. It should be pointed out that the fine structure is pretty much different compared with manganese oxides ${ }^{36}$ leading to the conclusion that the manganese ions are indeed embedded in the $\mathrm{N}_{x}$ environment.

To quantify the density of active adsorption sites at the surface of the catalysts, $\mathrm{CO}$ pulse chemisorption experiments at $193 \mathrm{~K}$ followed by TPD of CO were carried out (see Supplementary Fig. 7 for instrumental details). Figure $4 \mathrm{a}$ reports the pulse chemisorption traces of all three final $\mathrm{Me}-\mathrm{N}-$ C-3HT-2AL catalysts, as well as two reference catalysts. The reference samples comprise the metal-free $\mathrm{N}-\mathrm{C}$ and the $\mathrm{Fe}-\mathrm{N}-\mathrm{C}-2 \mathrm{HT}-1 \mathrm{AL}$ catalyst, which is the mother sample of $\mathrm{Fe}-\mathrm{N}-\mathrm{C}-3 \mathrm{HT}-2 \mathrm{AL}$.
The CO pulse chemisorption data provide two new important insights: first, there is no detectable adsorption of $\mathrm{CO}$ on the metal-free $\mathrm{N}-\mathrm{C}$ sample, implying that $\mathrm{CO}$ adsorption on metalfree nitrogen functionalities is negligible or below our detection limits for the given experimental conditions. Second, the amount of adsorbed CO increased with the ORR activity. We are inclined to conclude that $\mathrm{CO}$ molecules adsorbed predominantly on surface sites relevant to ORR catalysis. This conclusion is further supported by the monotonic correlation between the molar amounts of adsorbed $\mathrm{CO}$ per $\mathrm{mg}_{\text {catalyst }}$ with the mass activities of the iron-based $\mathrm{Me}-\mathrm{N}-\mathrm{C}$ catalysts in acid in Fig. 4b. Previously unaddressed, this correlation and its monotonic character tend strong evidence to our claim of probing catalytically active sites in each sample.

To learn more about the chemical bonding of CO to catalytic surface sites, we conducted TPD experiments of the three Me-N-C catalysts (Fig. 4c). The TPD data show that the CO desorption temperature (and rate) is sensitive to the specific nature of the metal, starting at 210 and $260 \mathrm{~K}$ for $\mathrm{Mn}-\mathrm{N}-\mathrm{C}-3 \mathrm{HT}-2 \mathrm{AL}$ and $\mathrm{Fe}-\mathrm{N}-\mathrm{C}-3 \mathrm{HT}-2 \mathrm{AL}$, respectively. The substantially higher desorption temperature of the iron-based catalyst suggests a larger desorption energy barrier, possibly related to a stronger $\mathrm{CO}$ binding on $\mathrm{Fe}$-containing moieties what could be an indication of a more favourable interaction with $\mathrm{O}_{2}$ as well. Interestingly, our bimetallic catalyst (Fe,Mn)-N-C-3HT2AL shows two separate desorption peaks. The slight down- and up-shift observed in the individual desorption peak temperatures of $\mathrm{Mn}$ and $\mathrm{Fe}$ sites in this bimetallic catalyst, respectively, seem to indicate some differences in their detailed CO desorption kinetics compared with the monometallic catalysts. Furthermore, comparing the experimental TPD peak integrals with the actual metal ratio of $\mathrm{Fe}: \mathrm{Mn}=3: 1$ (Supplementary a

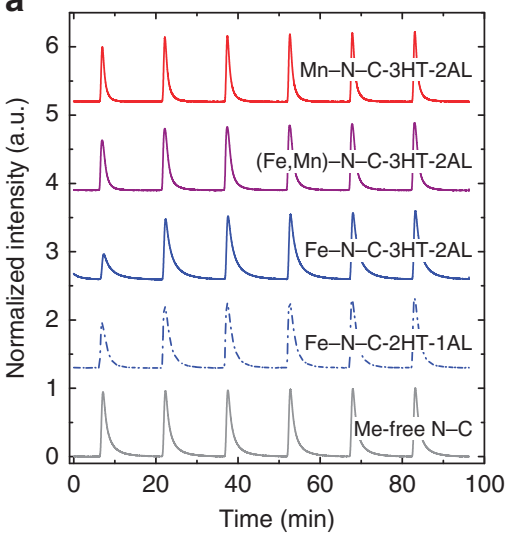

C

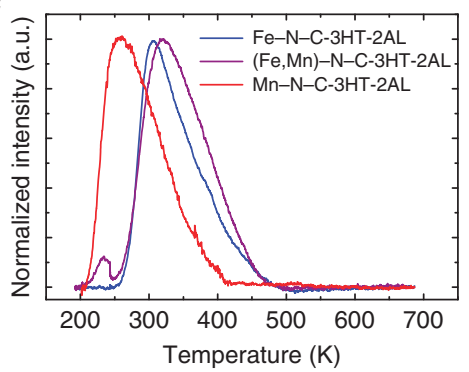

b

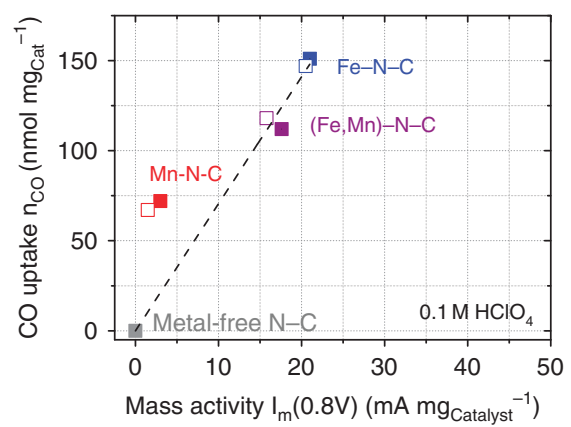

d

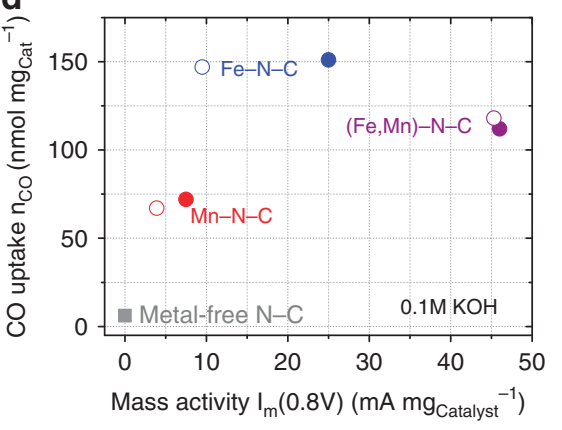

Figure 4 | Results obtained from CO sorption. (a) Carbon monoxide (CO) pulse chemisorption profiles of $\mathrm{N}-\mathrm{C}$ (blank catalyst; grey trace), $\mathrm{Fe}-\mathrm{N}-\mathrm{C}-2 \mathrm{HT}-1 \mathrm{AL}$ (dashed blue trace), Fe-N-C-3HT-2AL (blue trace), (Fe, Mn)-N-C-3HT-2AL (violet trace), Mn-N-C-3HT-2AL (red trace); CO uptake (nmol $\mathrm{mg}_{\text {catalyst }}^{-1}$ ) versus ORR catalyst mass activity $\mathrm{I}_{\mathrm{m}}$ at $0.8 \mathrm{~V}(\mathrm{~mA} \mathrm{mg}-1$ catalys $)$ in (b) $0.1 \mathrm{M} \mathrm{HClO}_{4}$ and in (d) $0.1 \mathrm{M} \mathrm{KOH}$ (filled symbols: after $3 \mathrm{HT}-2 \mathrm{AL}$, open symbols: after 2HT-1AL), (c) Normalized temperature-programmed desorption (TPD) profiles of Fe-N-C-3HT-2AL (blue line), (Fe,Mn)-N-C-3HT2AL (violet line), and Mn-NC3HT-2AL (red line), Conditions: CO adsorption at $193 \mathrm{~K}$, desorption ramp: $20 \mathrm{~K}$ min $^{-1}$ to $693 \mathrm{~K}$. a.u., arbitrary unit. 
Table 3) suggests that most of the $\mathrm{CO}$ molecules appear to be adsorbed on Fe sites in the bimetallic (Fe,Mn)-N-C-3HT-2AL catalyst. Finally, our present TPD results reasonably explain why previous attempts to probe or block the catalytically active sites of non-precious Me-N-C ORR catalysts by $\mathrm{CO}$ failed $^{27}$ : those experiments were performed at room temperature throughout, which is why the interaction of $\mathrm{CO}$ with the metal active sites was too weak to enable chemical adsorption. Significantly lower temperatures are required. One might suspect that a further decrease in temperature might enable to probe even metal-free $\mathrm{N}-\mathrm{C}$ sites that are ORR active in alkaline and at higher over potentials in acid.

\section{Discussion}

We have applied two distinctly different analysis techniques that is $\mathrm{CO}$ adsorption and Mössbauer spectroscopy. Now, we address the quantification of mass-based surface active-site density, MSD and $\mathrm{TOF}_{\mathrm{CO}}$, values based on accessible surface sites probed by $\mathrm{CO}$ chemisorption. The $\mathrm{TOF}_{\mathrm{CO}}$ values derived from $\mathrm{CO}$ pulse chemisorption were calculated by dividing catalyst mass activities $I_{\mathrm{m}}$ at $+0.8 \mathrm{~V}$ versus RHE by the molar amount of adsorbed CO molecules $n_{\mathrm{CO} \text {, Catalyst }}$ and the Faradaic constant $\mathrm{F}$ according to

$$
\mathrm{TOF}_{\mathrm{CO}}(+0.8 \mathrm{~V})=I_{\mathrm{m}} \cdot F^{-1} \cdot n_{\mathrm{CO}, \text { Catalyst }}^{-1}
$$

The $\mathrm{TOF}_{\mathrm{CO}}$ values in acid and alkaline are plotted as solid and hatched bars, respectively, in Fig. 5a. As shown in Fig. 4a, the metal-free $\mathrm{N}-\mathrm{C}$ catalyst does not indicate any $\mathrm{CO}$ adsorption. Consequently, this method of calculating the TOF values is only applicable to $\mathrm{Me}-\mathrm{N}-\mathrm{C}$ catalysts. In addition, it should be noted that possibly our $\mathrm{CO}$ adsorption experiment was not performed at the saturation point, that is, it is possible that not all sites are probed by $\mathrm{CO}$ adsorption at $-80^{\circ} \mathrm{C}$ and lower temperatures would be required to reach saturation. Hence, the obtained TOFs display upper limits for these catalysts.

In acidic environment, the $\mathrm{TOF}_{\mathrm{CO}}$ values were similar for both iron-containing catalysts (1.5 electrons per site per s). Hence, it appears that the bimetallic nature has no impact on the ORR characteristics in acid, while we have seen that it substantially improves the catalyst stability during ASTs in acidic electrolyte (Fig. 2). This observation is in line with previously reported trends by $\mathrm{Wu}$ et al. ${ }^{5,9,37}$, where bimetallic PANI-Me-C-derived catalysts $(\mathrm{Me}=\mathrm{Fe}$ and $\mathrm{Co})$ were more stable compared with the Fe-only ones ${ }^{5}$. Considering that both the $\mathrm{Fe}$ and the $\mathrm{Mn}$ monometallic catalysts showed similar final metal contents, while the ORR activity was significantly smaller for the $\mathrm{Mn}-\mathrm{N}-\mathrm{C}-3 \mathrm{HT}-2 \mathrm{AL}$ catalyst, we conclude that a smaller fraction of active sites in the $\mathrm{Mn}-\mathrm{N}-\mathrm{C}$ catalyst is surface accessible for $\mathrm{O}_{2}$ or $\mathrm{CO}$ molecules. In addition, its significantly smaller TOF is in line with theoretical calculations performed for $\mathrm{MeN}_{4}$ sites in pyridinic and pyrrolic environment ${ }^{38}$.

In alkaline environment, the $\mathrm{TOF}_{\mathrm{CO}}$ values of metal sites exceeded nearly always those obtained in acidic environment, in accordance with earlier reports on $\mathrm{pH}$ effects in non-precious ORR catalysis ${ }^{39-41}$. The discrepancy between our optimized ironcontaining catalysts (3HT-2AL) and $\mathrm{Mn}-3 \mathrm{HT}-2 \mathrm{AL}$, however, is more distinct in alkaline environment (variation between 1.1 and 4.5 electrons per site per s). One reason might be given by the additional contribution of other sites that reveal a pronounced ORR activity in alkaline but not in acidic environment, as for instance nitrogen functionalities or quinone groups that might not be probed by $\mathrm{CO}$ under our given experimental conditions $^{42-46}$. A comparison of our TOF values with literature is limited, as so far there were no TOF values based on a surface-sensitive probe. Reported values were derived from
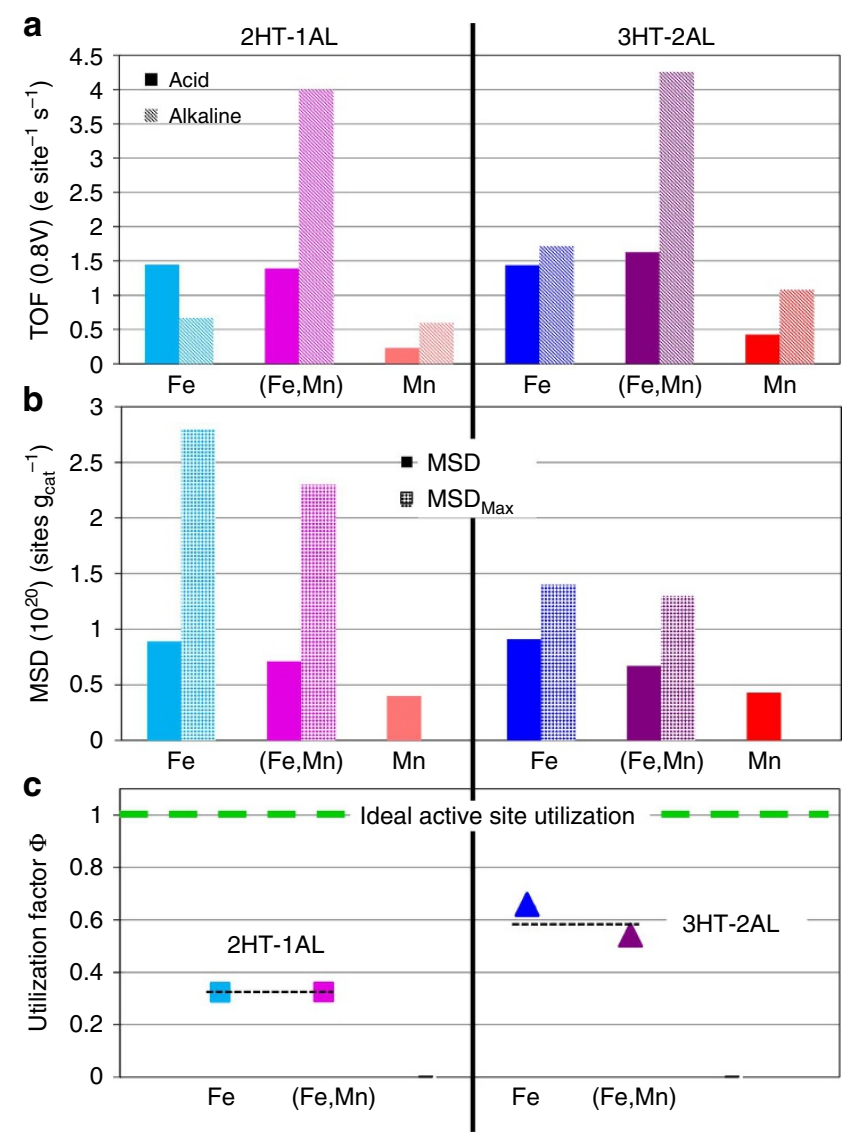

Figure 5 | Comparison of catalytic parameters. (a) Comparison of the turn-over frequency (TOF) values as derived from CO chemisorption (TOF) in acid and alkaline electrolytes. (b) Comparison of the mass-based surface active and maximum site densities derived from CO chemisorption (MSD) and Mössbauer spectroscopy $\left(\mathrm{MSD}_{\text {Max }}\right)$, respectively. (c) The active-site utilization factor $\Phi_{\mathrm{CO} / \mathrm{MBS}}$ as defined in equation 4 is plotted for the $\mathrm{Fe}-\mathrm{N}-\mathrm{C}$ and $(\mathrm{Fe}, \mathrm{Mn})-\mathrm{N}-\mathrm{C}$ catalysts with $3 \mathrm{HT}-2 \mathrm{AL}$ and with $2 \mathrm{HT}-1 \mathrm{AL}$, its distance to the horizontal dashed line represents a quantitative measure of the promise of a particular catalyst material and catalyst preparation method (ideal utilization $\Phi_{\mathrm{CO} / \mathrm{MBS}}=1$ ).

Mössbauer spectroscopy or just from the relation of ORR current densities towards the overall concentration of metal in these Me-N-C-catalysts ${ }^{16,17,20,30,47}$.

Comparing our values with those previously reported, we achieve one of the highest TOF values for NPMC. The only TOF value that exceeds ours is related to a binary active site composed of a high-spin $\mathrm{NFeN}_{2+2}$ site interacting with a protonated nitrogen group reported by Dodelet's group: $\mathrm{NFeN}_{2}+2 \ldots \mathrm{NH}^{+} / \mathrm{C}$ $(\mathrm{TOF}(0.8 \mathrm{~V}) \approx 10 \text { electrons per site per } \mathrm{s})^{20}$. This particular site, however, undergoes a very fast degradation due to anion binding that limits its applicability to the fuel cell technology so $\operatorname{far}^{2,11,20,48,49}$. Hence, we emphasis that our catalysts combine auspicious TOF values and a relatively stable performance. In addition, it should be noted that the real intrinsic TOF might even be higher as the accessibility of the active sites in our CO adsorption experiment might be significantly better compared with real operating conditions that limit $\mathrm{O}_{2}$ diffusion.

Beside the TOF, the density of active sites is another important parameter for the optimization of catalysts. If each catalytic active site is blocked by one $\mathrm{CO}$ molecule, the molar amount of adsorbed CO per $\mathrm{mg}_{\text {catalyst }} n_{\mathrm{CO}}$ (in nmol mg ${ }^{-1}$ ) equals the molar concentration of active surface sites contributing to the ORR process. By multiplying the measured values with Avogardo's 
constant $\mathrm{N}_{\mathrm{A}}$, we get the mass-based surface site density MSD (2).

$$
\operatorname{MSD}\left[\text { sites } \mathrm{g}_{\text {cat }}^{-1}\right]=n_{\mathrm{CO}}\left[\mathrm{nmol} \mathrm{mg}^{-1}\right] \times 10^{-6} \times \mathrm{N}_{\mathrm{A}}
$$

We would now like to compare our $\mathrm{CO}$ chemisorption derived mass-based site densities, MSD, with analogous mass-based site densities, derived from Mössbauer spectroscopy. However, we would like to point out the difference in the distinct probing characteristics of both methods: Mössbauer spectroscopy is a bulk method probing the total density of specific Fe sites, typically deviating from the number of $\mathrm{Fe}$ sites actually accessible for adsorption of $\mathrm{O}_{2}$ or $\mathrm{CO}$ molecules. Indeed, it was shown previously for $\mathrm{Fe}-\mathrm{N}-\mathrm{C}$ catalysts that fractions of D1-related sites are 'hidden' in the bulk of the material and consequently do not contribute to the ORR activity ${ }^{16,30}$. As such, the amount of the D1-related $\mathrm{FeN}_{4}$ sites provides a measure of the maximum number of possible ORR active sites referred to as the maximum mass-based site density $\mathrm{MSD}_{\max }$, given the perfect accessibility to all active $\mathrm{FeN}_{4}$ sites. Based on previous reported correlations between ORR activity and our D1 motif, we exclusively ascribe the ORR activity to the D1-related $\mathrm{FeN}_{4}$ species ${ }^{16,17,30}$. Furthermore, based on TPD results, we deduce that for $(\mathrm{Fe}, \mathrm{Mn})-\mathrm{N}-\mathrm{C}-3 \mathrm{HT}-2 \mathrm{AL}$ most of the ORR activity is related to the D1 motif. Accordingly, under the precondition of similar Debye-Waller factors, the maximum mass-based site density $\mathrm{MSD}_{\max }$ can be calculated from Mössbauer spectroscopy by equation (3):

$$
\operatorname{MSD}_{\max }\left[\operatorname{sites~}_{\text {cat }}^{-1}\right]=\mathrm{Fe}_{\mathrm{DI}}[\mathrm{wt} \%] / 100 / M_{\mathrm{Fe}}\left[\mathrm{g} \mathrm{mol}^{-1}\right] \times \mathrm{N}_{\mathrm{A}}\left[\mathrm{mol}^{-1}\right]
$$

Here, $\mathrm{Fe}_{\mathrm{D} 1}$ [wt\%] denotes the iron concentration of the D1 motif (Supplementary Table 4), $\mathrm{M}_{\mathrm{Fe}}$ the molar mass of iron and $\mathrm{N}_{\mathrm{A}}$ Avogardo's constant. Figure 5b compares these mass-based site densities of our $\mathrm{CO}$ chemisorption experiments with those that are derived from Mössbauer spectroscopy.

We would like to point out that the exclusive assignment of ORR activity to D1 was based on the following requirements that we demand for an ORR active site: (1) a significant contribution of the site to the ORR based on structure activity correlation and (2) the correlation should be of general nature and hold for differently prepared catalysts rather than just a single preparation route. A contribution of D2 can be excluded due to previous results ${ }^{11,16,17,30}$. The D3 and D4 motifs were not present in $\mathrm{Me}-\mathrm{N}-\mathrm{C}$ catalysts so far. A significant contribution of D4 to the ORR activity of these catalysts is excluded by the fact that this site is only present in the iron-based catalyst with a substantial amount. Hence, if it contributes to the ORR, the mass-related activity of $\mathrm{Fe}-\mathrm{N}-\mathrm{C}-3 \mathrm{HT}-2 \mathrm{AL}$ should be reasonably higher compared with $(\mathrm{Fe}, \mathrm{Mn})-\mathrm{N}-\mathrm{C}-3 \mathrm{HT}-2 \mathrm{AL}$ in both electrolytes. Notably, this is not the case. Taking into account, also the D3 motif would lead to even higher maximum mass-related site densities $\mathrm{MSD}_{\max }$ in our catalysts (but consequently lower utilization factors, see below). For reasons of comparison, we have included two columns in Supplementary Table 7 that give the maximum mass-based site densities $\left(\mathrm{MSD}_{\max }\right)$ either considering all $\mathrm{FeN}_{4}$ sites or only the D1-related $\mathrm{FeN}_{4}$ sites.

To characterize the catalyst performance and their possible enhancement through optimizing the catalyst surface area and mass-based site density, we introduce the ratio

$$
\Phi_{\mathrm{CO} / \mathrm{MBS}}=\mathrm{MSD} / \mathrm{MSD}_{\max }
$$

to represent an active-site utilization factor quantifying what ratio of the total number of catalytically active sites in a catalyst is actually accessible for the ORR. This utilization factor $\Phi_{\mathrm{CO} / \mathrm{MBS}}$ is plotted for the Fe-containing catalysts in Fig. 5c. Evidently, $\Phi_{\mathrm{CO} / \mathrm{MBS}}$ are very similar for each two catalysts after $2 \mathrm{HT}-1 \mathrm{AL}$ and 3HT-2AL, which supports the notion of $\Phi_{\mathrm{CO} / \mathrm{MBS}}$ representing an experimental meaningful descriptor for physically possible additional activity enhancements. To illustrate this, we point to the green dashed line in Fig. $5 c$ with $\Phi_{\mathrm{CO} / \mathrm{MBS}}=1$, which represents the optimal utilization of $\mathrm{Fe}$ sites in $\mathrm{Me}-\mathrm{N}-\mathrm{C}$ catalysts. In this case, all active Fe sites in a catalyst would be accessible by $\mathrm{O}_{2}$ (and CO) and contribute to the ORR process. Similarly, $\Phi_{\mathrm{CO} /}$ MBS offers projections of the maximum achievable catalyst current density of a specific family of catalysts, by dividing the experimentally observed mass activity by $\Phi_{\mathrm{CO} / \mathrm{MBs}}$. This is important as such projections allow a rapid and objective assessment and comparison of the theoretical promise of a specific preparation route or of specific precursors.

For the materials used here, our analysis uncovers that the mass activities could be further enhanced by a factor of $1.5 \mathrm{x}$ (for Fe-N-C-3HT-2AL) and 1.9x (for (Fe,Mn)-N-C-3HT-2AL) provided a suitable preparation. This enhancement could be realized by optimizing the catalyst dispersion such that all active sites are located on accessible pore surfaces. For a better evaluation of the utilization factor, Mössbauer spectroscopy was also applied to the two iron-containing catalysts with $2 \mathrm{HT}-1 \mathrm{AL}$. Their TOFs, mass-based site densities and the utilization factors are given in Fig. 5, too. The Mössbauer spectra are shown in Supplementary Fig. 5. Both catalysts contain the same iron species in approximately similar ratios as after $3 \mathrm{HT}-2 \mathrm{AL}$. The similar Mössbauer signatures indicate that there are no significant electronic changes induced by the $\mathrm{HT}$ and AL cycle. Consequently, the TOF values and mass-based surface activesite densities after $2 \mathrm{HT}-1 \mathrm{AL}$ and after $3 \mathrm{HT}-2 \mathrm{AL}$ are similar for both catalysts $(\mathrm{Fe}$ and $(\mathrm{Fe}, \mathrm{Mn}))$. In contrast, the maximum massbased site densities derived from Mössbauer spectroscopy are significantly larger for $2 \mathrm{HT}-1 \mathrm{AL}$ compared with $3 \mathrm{HT}-2 \mathrm{AL}$. This indicates that for these catalysts basically the ratio of surface accessible and hidden in the bulk active sites has changed, which is induced by the repeated HT and AL cycle. Furthermore, we would like to point out that due to the similarity in the preparation routine also the utilization factors are basically determined by the number and kind of HT and AL cycles. Our results indicate that the last HT-AL cycle was not beneficial for the iron-containing catalysts in terms of the maximum massbased site density $\mathrm{MSD}_{\max }$. Due to the AL that was involved not only inactive but to the same degree active sites were removed. Hence, the utilization of active sites should have been improved by another approach to enhance the ORR activity. In contrast, assuming by similarity of these three metal combinations similar $\Phi_{\mathrm{CO} / \mathrm{MBS}}$ factors for the $\mathrm{Mn}-\mathrm{N}-\mathrm{C}$ catalysts the change in the utilization factor going from $2 \mathrm{HT}-1 \mathrm{AL}$ to $3 \mathrm{HT}-2 \mathrm{AL}$ equals the increase in ORR activity ( $\Phi$ enhancement: 1.9, ORR enhancement: 2.0).

Beside the importance of the utilization factor for the catalyst activity (and the number of sites contributing), we believe that the utilization factor will be an important descriptor for the catalyst stability in the general concept of heterogeneous catalysis. For example, the 'stable' performance of the PANI-Fe-C catalyst in a potentiostatic test at $0.6 \mathrm{~V}$, as described by Ferrandon et al., was related to a balance of active-site destruction and utilizing active sites that were previously hidden in the bulk ${ }^{50}$. Consequently, the utilization factor $\Phi$ was significantly smaller than 1 at the beginning of the experiment and should come close to one at the time where the activity starts to decrease. Or in other words, during FC application, the activity decreases as soon as active-site destruction, and the utilization of hidden sites is not balanced anymore.

In conclusion, our combined analysis of non-precious ORR catalysts using CO adsorption and Mössbauer spectroscopy offers a previously unachieved quantification of active-site density and 
intrinsic TOF activity descriptors. The two experimentally accessible site density values yielded an active-site utilization factor $\Phi_{\mathrm{CO} / \mathrm{MBS}}$ that serves as a quantitative descriptor for the promise and potential of a specific chosen preparation technique with respect to its activity and stability. As such, $\Phi_{\mathrm{CO} / \mathrm{MBs}}$ enables an accelerated screening of the potential of different catalyst preparation techniques and, hence, is of general importance for future advances in the development of Fe-containing non-precious ORR catalysts.

\section{Methods}

Synthesis. Synthesis of Me-N-C catalysts involved a multistep preparation that is schemed in Supplementary Fig. 1. For the Fe-N-C-3HT-2AL catalyst, $3 \mathrm{~g} \mathrm{FeCl}_{3}$ was added into $2 \mathrm{ml}$ of pure aniline (Sigma-Aldrich) dissolved in $250 \mathrm{ml} 0.5 \mathrm{M} \mathrm{HCl}$. This solution was kept stirring for $1 \mathrm{~h}$ at $4{ }^{\circ} \mathrm{C}$. Thereafter, $5 \mathrm{~g}$ APS $\left(\left(\mathrm{NH}_{4}\right)_{2} \mathrm{~S}_{2} \mathrm{O}_{8}\right)$, as the oxidant, was added drop wise to inform the in situ polymerization of aniline. Finally, Ketjenblack EC-300 J (0.4 g), which was treated first in $0.5 \mathrm{M} \mathrm{HCl}$ (at room temperature, $24 \mathrm{~h})$, then refluxed in concentrated nitric acid $\left(90^{\circ} \mathrm{C}, 5 \mathrm{~h}\right)$ and subsequently washed with $\mathrm{H}_{2} \mathrm{O}$ was mixed with $\mathrm{FeCl}_{3} / \mathrm{PANI}$ under constant stirring. The mixture was kept under continuous stirring at room temperature for $48 \mathrm{~h}$. The desired product was then refluxed and vacuum dried to obtain the precursor powder. To achieve the final catalyst, $3 \mathrm{HT}$ steps and 2ALs were performed (compare Supplementary Fig. 1). The first HT (pyrolysis) for $1 \mathrm{~h}$ and the second and third $\mathrm{HTs}$ for $3 \mathrm{~h}$ performed in $\mathrm{N}_{2}$ at $900^{\circ} \mathrm{C}$. Each AL was made at $90{ }^{\circ} \mathrm{C}$ in $2 \mathrm{M} \mathrm{H}_{2} \mathrm{SO}_{4}$ for $5 \mathrm{~h}$, followed by filtration and rinsing with water (until neutralisation), whereas each preparation was finalized by a HT step. Hence the $\mathrm{Fe}-\mathrm{N}-\mathrm{C}-3 \mathrm{HT}-2 \mathrm{AL}$ had the following sequence of preparation steps:

$\mathrm{HT} 1-\mathrm{AL} 1-\mathrm{HT} 2-\mathrm{AL} 2-\mathrm{HT} 3$.

$\mathrm{MnCl}_{2}$ was used as the metal precursor for Mn-based catalysts. For bimetallic catalyst, a molar ratio of $\mathrm{Mn}: \mathrm{Fe}=1: 1$ was chosen as the optimal metal ratio. The nomenclature is similar to the iron-based catalysts.

The metal-free reference catalyst was prepared similarly, but without any metal chloride during the oxidative polymerization. In this case, the starting precursors went through a HT in $\mathrm{N}_{2}$ at $900^{\circ} \mathrm{C}$ for $1+3 \mathrm{~h}$ (hence, the duration at $900{ }^{\circ} \mathrm{C}$ was similar compared with $\mathrm{Fe}-\mathrm{N}-\mathrm{C}-2 \mathrm{HT}-1 \mathrm{AL}$ ).

RDE experiments. The catalyst ink was prepared by mixing $15.7 \mathrm{mg}$ of catalyst powder with $800 \mu \mathrm{l} \mathrm{H}_{2} \mathrm{O}, 150 \mu \mathrm{l}$ isopropanol and $50 \mu \mathrm{l}$ Nafion (5 wt\%). This mixture was ultrasonicated with an US-finger for $15 \mathrm{~min}$ while the ink was placed in an ice bath. From this homogeneous ink, $10 \mu \mathrm{l}$ were dropped on a glassy carbon disc with a diameter of $5 \mathrm{~mm}$ yielding a catalyst loading of $0.8 \mathrm{mg} \mathrm{cm}^{-2}$ for the NPMC. The Nafion to catalyst ratio was 1:4. Cyclic voltammetry was first performed at $10 \mathrm{mV} \mathrm{s}^{-1}$ in $\mathrm{N}_{2}$-saturated electrolyte at 1,500 r.p.m. Then, the solution was saturated with oxygen and linear sweep voltammetry was recorded with $10 \mathrm{mV} \mathrm{s}^{-1}$ at 1,500 r.p.m. Catalyst mass activity $\left(I_{\mathrm{m}}\right)$ in units of $\mathrm{mA} \mathrm{mg}$ catalyst was calculated according to $I_{\mathrm{m}}=I_{\text {kin }} / L_{\text {catalyst }}$, where $L_{\text {catalyst }}$ is the geometric catalyst loading $\left(\mathrm{mg}_{\text {catalyst }} \mathrm{cm}^{-2}\right.$ geo $)$ and $I_{\text {kin }}$ is the geometric kinetic current density, which was estimated according to: $I_{\text {kin }}=I_{0.8} \times I_{\lim } /\left(I_{\lim }-I_{0.8}\right)$, using the geometric current density at $0.8 \mathrm{~V}$ versus RHE, $I_{0.8}$, and the diffusion limited current density, $I_{\mathrm{lim}}$. Stability tests were performed up to 9,000 potential cycles in the potential range between 0.5 and $1.3 \mathrm{~V}$ versus RHE in $\mathrm{N}_{2}$-saturated electrolyte with the scan rate of $50 \mathrm{mV} \mathrm{s}^{-1}$ on stationary electrode. All activity and stability tests were performed at room temperature in $0.1 \mathrm{M} \mathrm{HClO}_{4}(\mathrm{pH} 1)$ and $0.1 \mathrm{M} \mathrm{KOH}$ ( $\mathrm{pH} 13$ ). All the results have been compared with a reference $\mathrm{Pt} / \mathrm{C}$ $20 \mathrm{wt} \%$ (E-TEK) catalyst with a geometric Pt loading of $10 \mu \mathrm{g}_{\mathrm{Pt}}$.

PEM-FC measurements. The Fe-N-C-3HT-2AL and the (Fe,Mn)-N-C-3HT$2 \mathrm{AL}$ catalysts were tested in the fuel cell cathode to evaluate their activity and durability under selected polymer electrolyte fuel cell conditions. The catalyst ink was prepared by ultrasonically mixing the catalyst powder with Nafion suspension (DE 2029, $20 \mathrm{wt} \%$ ) for $30 \mathrm{~min}$. The as-prepared ink was applied to the gas diffusion layer by successive spray-painting until the cathode catalyst loading reached ca. $2 \mathrm{mg} \mathrm{cm}^{-2}$ for NPMC and $0.2 \mathrm{mg}_{\mathrm{Pt}} \mathrm{cm}^{-2}$ as homogeneous catalyst films were formed. The Nafion content in the dry catalyst layer was maintained at ca. $50 \mathrm{wt} \%$. At the anode, Pt $46 \mathrm{wt} \%$ (TKK Japan, $0.25 \mathrm{mgPt} \mathrm{cm}^{-2}$ loading) was used. The same spray-painting method was used to form the anode layer. The cathode and anode were hot pressed onto two sides of one piece of a Nafion NRE 212 membrane. The geometric membrane electrode assembly (MEA) area was $10.0 \mathrm{~cm}^{2}$. Fuel cell testing was carried out in a single cell. Pure hydrogen and oxygen, humidified at $80^{\circ} \mathrm{C}$ were supplied to the anode and cathode (relative humidity 100\%). Noteworthy, the same absolute pressure of 1 bars was applied to both electrodes. Fuel cell polarization plots were recorded using a fuel cell test station (Fuel Cell Technologies, Inc.). Recorded voltage was corrected for the resistance of the Nafion membrane as well as the recorded current was corrected for hydrogen cross over. The MEA voltage cycling tests were carried out by flow of nitrogen to the cathode in the voltage range of $0.6-1.0 \mathrm{~V}$.
CO pulse chemisorption and TPD. Pulse chemisorption and TPD experiments were performed utilizing a Thermo scientific TPD/R/O 1110 instrument (depicted in Supplementary Fig. 7) under a helium flow of $20 \mathrm{ml} \mathrm{min}^{-1}$ as carrier gas. For each catalyst, an amount of $100-150 \mathrm{mg}$ was mounted between quartz wool in a quartz reactor assembling in a furnace (Supplementary Fig. 7). The temperature was measured at the sample position with a K-type thermocouple sealed in a quartz capillary. All samples were thermally pre-treated to remove any possible surface contamination, which can originate from adsorption of undesired molecules such as carbon species or water present in air. All adsorption processes in pulse chemisorption and TPD were carried out at $193 \pm 5 \mathrm{~K}$ by keeping the reactor in a bath of acetone and dry ice. In pulse chemisorption, $\mathrm{CO}$ consumption and in TPD the desorbed gas can be monitored through a thermal conductivity detector. The $\mathrm{CO}$ molecules are dragged by the carrier gas to thermal conductivity detector that measures the signal difference of the desorbed gas versus a reference flow. TPD experiments were carried out up to $693 \mathrm{~K}$ with a linear temperature ramp of $20 \mathrm{~K} \mathrm{~min}^{-1}$.

${ }^{57} \mathrm{Fe}$ Mössbauer spectroscopy. Measurements were made for $\mathrm{Fe}-\mathrm{N}-\mathrm{C}$ and (Fe,Mn)-N-C catalysts after 3HT-2AL and 2HT-1AL. About 75-100 mg of each sample were filled into an aluminium sample holder with a diameter of $1.5 \mathrm{~cm}$ and a height of $3 \mathrm{~mm}$. The sample holder is closed on both sides by Tesa tape. Hence, in the path of the $\gamma$-ray $10-30 \mu \mathrm{g}_{\mathrm{Fe}-57} \mathrm{~cm}^{-2}$ were present. Each sample was measured for about 10 days in two separate periods. The obtained spectra were qualitatively the same. To reduce noise the spectra were overlayed. Measurements were performed at room temperature with a 1,024 multichannel analyser equipped with a constant electronic drive system with triangular reference waveform (Halder Electronics, Germany). The Mössbauer relevant $\gamma$-radiation was provided by a $50 \mathrm{mCi} \mathrm{Co} / \mathrm{Rh}$ source. Calibration of the velocity scale was made with respect to an $\alpha$-Fe foil. Spectra were fitted with the programme Recoil assuming lorentzian line shape of all absorption sites.

Determination of chemical composition. X-ray-induced photoelectron spectroscopy was carried out on an AXIS ULTRA DLD (Shimadzu) with monochromated $\mathrm{Al} \mathrm{K}{ }_{\alpha} \mathrm{X}$-rays as the excitation source. Peak positions were internally referenced to the $\mathrm{C} 1 \mathrm{~s}$ peak at $284.6 \mathrm{eV}$. Fitting of the N1s fine scans were made with the UNIFIT software with $30 \%$ Lorentzian line form in the fitting process. In addition, the surface-near elemental composition was determined.

Determination of metal contents. Initial and final metal contents were determined by optical emission spectroscopy using inductive-coupled plasma as ionization source, which was performed by Varian 715-ES. The samples were pre-treated by microwave at $180^{\circ} \mathrm{C}$ to digest all moieties of the catalyst including carbon support. In a typical inductive-coupled plasma as ionization source sample preparation, $\sim 5 \mathrm{mg}$ of the dry sample powder was weighted in a quartz tube and dissolved in a mixture of concentrated acids including: $2 \mathrm{ml}$ sulphuric $(98 \mathrm{wt} \%)$, $2 \mathrm{ml}$ nitric $(69 \mathrm{wt} \%)$ and $6 \mathrm{ml}$ chloric (37 wt\%) acids. Sample digesting was performed by Microwave (CEM SP-D Discover) at $120^{\circ} \mathrm{C}$ for $10 \mathrm{~min}$.

\section{References}

1. Rahman, M. A., Wang, X. J. \& Wen, C. E. High energy density metal-air batteries: a review. J. Electrochem. Soc. 160, A1759-A1771 (2013).

2. Proietti, E. et al. Iron-Based Cathode Catalyst with Enhanced Power Density in Polymer Electrolyte Membrane Fuel Cells. Nat. Commun. 2, 416 (2011).

3. Strasser, P. in Chemical Energy Storage (ed. Schloegl, R.), 163-184 (De Gruyter, 2012).

4. Vielstich, W., Lamm, W. \& Gasteiger, H. (eds) in Handbook on Fuel Cells: Fundamentals, Technology, Applications 4-Vol, 3826 (Wiley, 2003).

5. Wu, G., More, K. L., Johnston, C. M. \& Zelenay, P. High-performance electrocatalysts for oxygen reduction derived from polyaniline, iron, and cobalt. Science 332, 443-447 (2011).

6. Spalek, O. et al. Oxygen trickle-bed electrode as a cathode for chloralkali electrolysis. J. Appl. Electrochem. 24, 751-757 (1994).

7. Serov, A., Robson, M. H., Smolnik, M. \& Atanassov, P. Tri-metallic transition metal-nitrogen-carbon catalysts derived by sacrificial support method synthesis. Electrochim. Acta 109, 433-439 (2013).

8. Tributsch, H., Koslowski, U. \& Dorbandt, I. Experimental and theoretical modeling of Fe-, Co-, Cu-, Mn-based electrocatalysts for oxygen reduction. Electrochim. Acta 53, 2198-2209 (2008).

9. Wu, G. \& Zelenay, P. Nanostructured Nonprecious Metal Catalysts for Oxygen Reduction Reaction. Acc. Chem. Res. 46, 1878-1889 (2013).

10. Jaouen, F. et al. Cross-laboratory experimental study of non-noble-metal electrocatalysts for the oxygen reduction reaction. ACS Appl. Mater. Interfaces 1, 1623-1639 (2009).

11. Kramm, U. I., Lefèvre, M., Larouche, N., Schmeisser, D. \& Dodelet, J.-P. Correlations between mass activity and physicochemical properties of $\mathrm{Fe} / \mathrm{N} / \mathrm{C}$ catalysts for the ORR in PEM fuel cell via 57Fe Mössbauer spectroscopy and other techniques. J. Am. Chem. Soc. 136, 978-985 (2014) 
12. Zhao, D. et al. Highly efficient non-precious metal electrocatalysts prepared from one-pot synthesized zeolitic imidazolate frameworks. Adv. Mater. 26, 1093-1097 (2014).

13. Cheon, J. Y. et al. Ordered mesoporous porphyrinic carbons with very high electrocatalytic activity for the oxygen reduction reaction. Sci. Rep. 3, 2715 (2013).

14. Ferrandon, M. et al. Multitechnique characterization of a polyaniline-ironcarbon oxygen reduction catalyst. J. Phys. Chem. C 116, 16001-16013 (2012).

15. Kattel, S., Atanassov, P. \& Kiefer, B. A density functional theory study of oxygen reduction reaction on non-PGM Fe-N-x-C electrocatalysts. Phys. Chem. Chem. Phys. 16, 13800-13806 (2014).

16. Koslowski, U. I., Abs-Wurmbach, I., Fiechter, S. \& Bogdanoff, P. Nature of the catalytic centres of porphyrin based electrocatalysts for the ORR-a correlation of kinetic current density with the site density of Fe- $\mathrm{N}_{4}$ centres. J. Phys. Chem. C 112, 15356-15366 (2008).

17. Kramm, U. I. et al. Influence of the electron-density of $\mathrm{FeN}_{4}$-centers towards the catalytic activity of pyrolysed FeTMPPCl-based ORR-electrocatalysts. J. Electrochem. Soc. 158, B69-B78 (2011).

18. Szakacs, C. E., Lefevre, M., Kramm, U. I., Dodelet, J.-P. \& Vidal, F. A density functional theory study of catalytic sites for oxygen reduction in $\mathrm{Fe} / \mathrm{N} / \mathrm{C}$ catalysts used in H2/O2 fuel cells. Phys. Chem. Chem. Phys. 16, 13654-13661 (2014).

19. Titov, A. et al. Catalytic Fe-xN Sites in Carbon Nanotubes. J. Phys. Chem. C 113, 21629-21634 (2009).

20. Kramm, U. I. et al. Structure of the catalytic sites in Fe/N/C-catalysts for $\mathrm{O}_{2}$-reduction in PEM fuel cells. Phys. Chem. Chem. Phys. 14, 11673-11688 (2012).

21. Goellner, V. et al. Degradation of Fe/N/C catalysts upon high polarization in acid medium. Phys. Chem. Chem. Phys. 16, 18454-18462 (2014).

22. Kramm, U. I., Lefèvre, M., Bogdanoff, P., Schmeißer, D. \& Dodelet, J.-P. Analyzing structural changes of $\mathrm{Fe}-\mathrm{N}-\mathrm{C}$ cathode catalysts in PEM fuel cell by Mößbauer spectroscopy of complete membrane electrode assemblies. J. Phys. Chem. Lett. 5, 3750-3756 (2014).

23. Artyushkova, K. et al. Density functional theory calculations of XPS binding energy shift for nitrogen-containing graphene-like structures. Chem. Commun. 49, 2539-2541 (2013).

24. Chung, H. T., Won, J. H. \& Zelenay, P. Active and stable carbon nanotube/ nanoparticle composite electrocatalyst for oxygen reduction. Nat. Commun. 4, 1922 (2013).

25. Zelenay, P. Non-Precious Metal Fuel Cell Cathodes: Catalyst Development and Electrode Structure Design. US Department of Energy, Energy Efficiency and Renewable Energy, Annual Merit Review meeting, Project ID: FC107 (2014).

26. Bae, I. T. \& Scherson, D. A. In situ X-ray absorption of a carbon monoxide-iron porphyrin adduct adsorbed on high area in an aqueous electrolyte. J. Phys. Chem. B 102, 2519-2522 (1998).

27. Birry, L., Zagal, J. H. \& Dodelet, J.-P. Does CO poison Fe-based catalysts for ORR? Electrochem. Commun. 12, 628-631 (2010).

28. Thorum, M. S., Hankett, J. M. \& Gewirth, A. A. Poisoning the oxygen reduction reaction on carbon-supported $\mathrm{Fe}$ and $\mathrm{Cu}$ electrocatalysts: evidence for metalcentered activity. J. Phys. Chem. Lett. 2, 295-298 (2011).

29. Jaouen, F. et al. Oxygen reduction activities compared in rotating-disk electrode and proton exchange membrane fuel cells for highly active FeNC catalysts. Electrochim. Acta 87, 619-628 (2013).

30. Kramm, U. I., Herrmann-Geppert, I., Bogdanoff, P. \& Fiechter, S. Effect of an ammonia treatment on structure, composition and ORR activity of Fe-N-C catalysts. J. Phys. Chem. C 115, 23417-23427 (2011).

31. Roelfes, G. et al. End-on and side-on peroxo derivatives of non-heme iron complexes with pentadentate ligands: Models for putative Intermediates in biological iron/dioxygen chemistry. Inorg. Chem. 42, 2639-2653 (2003).

32. Greenwood, N. N. \& Gibb, T. C. Mössbauer Spectroscopy 1 edn, Vol. 1 (Chapman and Hall Ltd., 1971).

33. Kramm, U. I. et al. Effect of iron-carbide formation on the number of active sites in $\mathrm{Fe}-\mathrm{N}-\mathrm{C}$ catalysts for the oxygen reduction reaction in acidic media. J. Mater. Chem. A 2, 2663-2670 (2014).

34. Herrmann, I. Entwicklung und Optimierung neuer Präparationsverfahren für Übergangsmetall-basierte Elektrokatalysatoren für die Sauerstoffreduktion. Dr. rer. nat. thesis, Freie Universität Berlin (2005).

35. Petraki, F. et al. Impact of the 3D electronic states of cobalt and manganese phthalocyanines on the electronic structure at the interface to $\mathrm{Ag}(111)$. J. Phys. Chem. C 115, 21334-21340 (2011).

36. Buhrmester, T. Zur Fehlordnung im System $\mathrm{Li}_{1+x} \mathrm{Mn}_{2-y} \mathrm{O}_{4-d}$. Dr. Ing. thesis, TU Darmstadt (2001).

37. Holby, E. F., Wu, G., Zelenay, P. \& Taylor, C. D. Structure of Fe-Nx-C defects in oxygen reduction reaction catalysts from first-principles modeling. J. Phys. Chem. C 118, 14388-14393 (2014).

38. Calle-Vallejo, F., Martinez, J. I. \& Rossmeisl, J. Density functional studies of functionalized graphitic materials with late transitions metals for oxygen reduction reactions. Phys. Chem. Chem. Phys. 13, 15639-15643 (2011).
39. Bukola, S. et al. Fe-N-C electrocatalysts for oxygen reduction reaction synthesized by using aniline salt and $\mathrm{Fe} 3+/ \mathrm{H} 2 \mathrm{O} 2$ catalytic system. Electrochim. Acta 146, 809-818 (2014).

40. Merzougui, B., Hachimi, A., Akinpelu, A., Bukola, S. \& Shao, M. A Pt-free catalyst for oxygen reduction reaction based on $\mathrm{Fe}-\mathrm{N}$ multiwalled carbon nanotube composites. Electrochim. Acta 107, 126-132 (2013).

41. Meng, H., Jaouen, F., Proietti, E., Lefèvre, M. \& Dodelet, J.-P. pH-effect on oxygen reduction activity of Fe-based electro-catalysts. Electrochem. Commun. 11, 1986-1989035 (2009).

42. Gojkovic, S. L., Gupta, S. \& Savinell, R. F. Heat-treated iron(III) tetramethoxyphenyl porphyrin chloride supported on high area carbon as an electrocatalyst for oxygen reduction part III: detection of hydrogen-peroxide during oxygen reduction. Electrochim. Acta 45, 889-897 (1999).

43. Golabi, S. M. \& Raoof, J. B. Catalysis of dioxygen reduction to hydrogen peroxide at the surface of carbon paste electrodes modified by 1,4-naphthoquinone and some of its derivates. J. Electroanal. Chem. 416, 75-82 (1996).

44. Mirkhalaf, F., Tammeveski, K. \& Schiffrin, D. J. Substituent effects on the electrocatalytic reduction of oxygen on quinone-modified glassy carbon electrodes. Phys. Chem. Chem. Phys. 6, 1321-1327 (2004).

45. Tammeveski, K., Kontturi, K., Nichols, R. J., Potter, R. J. \& Schiffrin, D. J. Surface redox catalysis for $\mathrm{O}_{2}$ reduction on quinone-modified glassy carbon electrodes. J. Electroanal. Chem. 515, 101-112 (2001).

46. Sidik, R. A., Anderson, A. B., Subramanian, N. P., Kumaraguru, S. P. \& Popov, B. N. $\mathrm{O}_{2}$ reduction on graphite and nitrogen-doped graphite: experimental and theory. J. Phys. Chem. B 110, 1787-1793 (2006).

47. Jaouen, F. \& Dodelet, J.-P. Turn-over frequency of $\mathrm{O}_{2}$ electro-reduction for $\mathrm{Fe} / \mathrm{N} / \mathrm{C}$ and $\mathrm{Co} / \mathrm{N} / \mathrm{C}$ catalysts in PEFCs. Electrochim. Acta. 52, 5975-5984 (2007).

48. Herranz, J. et al. Unveiling N-protonation and anion-binding effects on $\mathrm{Fe} / \mathrm{N} / \mathrm{C}$-catalysts for $\mathrm{O} 2$ reduction in PEM fuel cells. J. Phys. Chem. C 115, 16087-16097 (2011).

49. Lefèvre, M., Proietti, E., Jaouen, F. \& Dodelet, J.-P. Iron-based catalysts with improved oxygen reduction activity in polymer electrolyte fuel cells. Science 324, 71-74 (2009).

50. Ferrandon, M. et al. Stability of iron species in heat-treated polyaniline-ironcarbon polymer electrolyte fuel cell cathode catalysts. Electrochim. Acta 110, 282-291 (2013).

\section{Acknowledgements}

Part of this work was financially supported by the German Federal Ministry of Education and Research (Bundesministerium für Bildung und Forschung, BMBF) under grant 03SF0531B, and by the Darmstadt Graduate School of Excellence Energy Science and Engineering (GSC 1070).

\section{Author contributions}

N.R.S. performed the synthesis of catalysts, EC characterization and CO chemisorption, U.I.K. characterized the samples by MBS, XANES and developed the model of the utilization factor. J.S., Y.Z., A.T., T.R., J.-P.P. performed the characterization of the catalysts by XPS, XRD, ICP and in parts the electrochemical characterization. The project was conceived and supervised by P.S., in parts assisted by U.I.K. The manuscript and supplementary information was written and edited by U.I.K. and P.S. All authors contributed to the discussion of the results.

\section{Additional information}

Supplementary Information accompanies this paper at http://www.nature.com/ naturecommunications

Competing financial interests: The authors declare no competing financial interests.

Reprints and permission information is available online at http://npg.nature.com/ reprintsandpermissions/

How to cite this article: Sahraie, N. R. et al. Quantifying the density and utilization of active sites in non-precious metal oxygen electroreduction catalysts. Nat. Commun. 6:8618 doi: 10.1038/ncomms9618 (2015).

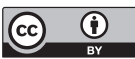

This work is licensed under a Creative Commons Attribution 4.0 International License. The images or other third party material in this article are included in the article's Creative Commons license, unless indicated otherwise in the credit line; if the material is not included under the Creative Commons license, users will need to obtain permission from the license holder to reproduce the material. To view a copy of this license, visit http://creativecommons.org/licenses/by/4.0/ 